\title{
STRATEGIC PLANNING WITH A SYSTEM DYNAMICS MODEL FOR REGIONAL TOURISM SITE DEVELOPMENT
}

\author{
Richard G. Fritz
}

\section{Introduction}

This research follows the dynamics of the leisure "service" production cycle of a tourism site through the nonlinear technique of system dynamics. System dynamic models use feedback relationships to interrelate observed data and descriptive information to understand the internal linkages among the competing forces of a system. The resulting simulation provides a long run forecast that can be used by policy makers in achieving a balanced strategic management plan. As with all system dynamics models, the purpose is to develop a quantitative simulation that depicts the structural relationships of the process under study. Public and private decision makers are concerned with the long run results of regional tourism site development. This research criticizes the current use of the product life cycle concept as applied in the market for services for its inability to consider the structural dynamics of the market. The structural dynamics are considered in the formal model developed here. The goal of this research is to provide insight into the use of system dynamics models as a tool for aiding in strategic decisions concerning regional tourism site development.

In the first section the relation between the product life cycle (PLC) concept and strategic support planning models (SSPM) is reviewed. The main abuses of the PLC concept as a tool for management decision making are noted, and the natural organism growth process from which the concept gets its foundation is reviewed. The limitations of PLC as a strategic tool lead to the second section where the nonlinear feedback modeling analysis of system dynamics is reviewed. The application of system dynamics to the PLC concept is described there. That section is followed by an argument for treating the development of a tourism site within the structure of the PLC concept. This requires translating the product life cycle theory from a market for goods into a PLC framework for the market for services. The model developed here may prove to be exportable to a variety of service market structures.

The third section focuses on the evolutionary nature of tourism development. The evolutionary view portrays

\footnotetext{
"Senior Economist, Research Department, Federal Home Loan Bank of Atlanta
}

tourism as an industry that promises many private and public economic benefits quickly, and thereby obscures the fact that negative impacts usually emerge during the latter stages of development of a site. There are three important considerations that contribute to the dynamics of the site. These include changes in the preferences and needs of the visitors (demand conditions), the gradual deterioration and possible replacement of physical plant and facilities (supply conditions), and the change in or disappearance of the original natural and cultural attractions that were responsible for the initial popularity of the area (interaction between supply and demand conditions). Over time, the type and volume of tourists change, the host culture changes, and the reactions of community residents to tourists vary in a predictable manner with stages of tourist attraction development.

The fourth section of the paper develops a general dynamic model that illustrates the feedbacks associated with the evolutionary stages described in section one. While the system dynamics model is designed to be generic, it is based on the general characteristics of theme park growth in Florida. The strategic management problem is focused on one of the mature theme parks in that state.

The last section of the paper reviews insights from the simulation results. The results are interpreted as strategy support, used to provide more effective assessment of strategic proposals. Such strategic support can provide sharper insight into the consequences of pursuing proposals formulated by decision maker intuition.

\section{The Service Product Life Cycle and Strategic Planning}

It is difficult to review a study on strategic planning without encountering the product life cycle (PLC) concept. Some authors argue that the concept often is abused and has application only when careful consideration is given to the difficulties of adapting this biological phenomenon to the inanimate world of the market (Hart, Casserly and Lawless, 1984). Yet the PLC concept is the foundation upon which most strategic planning models are based (Sirkis and Race, 1981; and Sheth, 1985). The appeal of PLC has resulted in attempts to borrow a seemingly useful theory from one scientific field and apply it to observations 
recorded in another field. The population growth cycle of a biological organism's population growth can be represented by an S-shaped curve. Adaptations of the S-curve model abound in both social science and business.

It is not necessary to look very far to find applications of the concept in tourism industry studies: hotels (Rushmore, 1984), resort island (Meyer-Arendt, 1985), island economy (McTaggart, 1980), and restaurants (Hart, Casserly and Lawless, 1984). The life of a marketable commodity or service usually is measured in dollar sales volume, arrivals, or attendance. The stages of that life include: introduction (slow growth and modest or negative profits), take-off (rapid growth and peak profits), maturity (growth eventually stops and profits contract), and decline (market saturation and failed product differentiation).

How can strategic planning be related to the PLC concept in tourism, specifically to the case of developing a resort site for the tourism market? Further, how can abuses of the PLC concept be avoided in this application? The confusion and abuse of applying the PLC concept to strategic planning results from two extreme interpretations. The first assumes that the market phenomena in question must have a life cycle similar to those of living organisms, with the stages of development discussed above. The other extreme assumes that there is no structure at all to the PLC because business activity always can be managed through timely and correct decisions.

It is important to note that strategic planning means different things to different people. In the marketing discipline, strategic planning refers to those efforts to differentiate a commodity or service from similar items or services offered by the competition. If a differentiated leisure market service is introduced to a market with highly successful results (reaching and completing the growth stage of the cycle), emulation of the product by competitors would be expected. The normal long run adjustment process in such a monopolistically competitive market would yield results similar to those depicted by the PLC model with the S-curve.

Thus, in marketing, strategic planning has the primary objective of predicting sales trends. The PLC concept was thought to have value not only when the sales trend was S-shaped, but when it was believed necessarily $\mathrm{S}$-shaped. This is the source of confusion over the usefulness of the PLC concept. Poor decisions stemmed from misunderstanding the relation between the PLC concept and the historical trend in sales. Early application of the PLC model constrained decisions because it was assumed that the item or service had embarked on the irreversible stage of decline (Dhalla and Yuspeh, 1976). Strategic planning authors then treated occasional product revivifications as "unnatural" behavior because the products were not acting like natural systems.

Another misuse of the PLC has been to treat it as "nothing more or less than a sales curve" (Hart, Casserly and Lawless, p. 57). This approach implies that there is nothing predetermined about PLC. The sales curve application adds further confusion by not distinguishing between the life cycle of a product and that of a "brand." A sales curve is the result of numerous market forces that combine uniquely in a given situation to produce an observed relation between sales and time. From the perspective of strategic planning in a service market, treating the PLC concept as equivalent to a sales curve implies that the PLC/sales curve can and should be managed by decision makers. The sales curve models and the PLC concept which requires an S-curve cycle have the same flaw. Neither has a dynamic mechanism that causes change.

In the broadest sense, strategic planning models must be representative of the long run dynamics of the process under analysis. In living organisms, the dynamics lies in the procreation of the biological species. There is little reason to believe that a mathematical process that simulates biological procreation would consistently represent the sales curve of a leisure service market (or any other type market). However, that means only that the process of strategic planning must identify the structural characteristics underlying the dynamics of the market under study. There well may be a causal structure that consistently promotes an S-curve sales behavior. The "time of adoption pattern" research in marketing has searched for this possibility. Oscillating sine wave sales behavior also may exist for other products in other market settings. Numerous structural deviations are possible. Indeed, the S-curve behavior could be an aggregate of several types of diffusion and feedback phenomena. Additionally, there is the confusion caused by short run stochastic influences that blur the interpretation of the empirical sales curve.

The market considered here is the leisure "service" of tourism. Tourism is less tangible and in some ways less subject to the potential burden of "old" and "new" technology updates than many services. However, "updates" may require significant levels of capital investment to renovate the service delivery vehicle. Technological innovation may be viewed as underlying the PLC, just as biochemistry may be seen as underlying living life cycle models, and as thermodynamic interactions can help explain the behavior of geological life cycle models. The tie of the leisure service offered by a tourism site to technology may be greatly loosened, however, and causal explanations for a PLC of services may be much weaker. Furthermore, as services are personal deliveries (or economic exchanges), the link between a PLC and a "brand" life cycle also is much weaker than it would be for a tangible commodity 
(Luck and Ferrell, 1985 pp. 353-354).

The goal of strategic planning is to see through the short run stochastic fluctuations to predict the long run planning curve faced by the service. This means that traditional time series forecasting techniques are of little value in developing long run strategic planning scenarios. However, the dynamic feedback modeling technique of system dynamics offers a useful tool for strategic analysis.

\section{Strategic Planning, PLC Concept and System Dynamics}

The use of system dynamics models in the development of strategic decision analysis is not unique to the market for leisure products. From Industrial Dynamics of Forrester (1961), to Corporate Planning and Policy Design, Lyneis (1981), to "Strategy Support Models" of Morecroft (1984) (for many other examples, see Wilber and Ellis, 1985), computer aided dynamic decision models have been developed that are either directly for strategic planning or that support analysis of policy decisions. This section follows closely the arguments used by Morecroft in his development of strategic support models.

An important adjustment in the Morecroft approach is in the role of the model. A successful approach to the evaluation of strategy utilizes the argument and debate of the dialectic method. The discussion generally is centered on the "mental models" of the team of decision makers assigned to the task. When the proposal is difficult to evaluate, good opinions can differ greatly. Thus the role of a formal model is to add another viewpoint to the dialectic process. Although the formal model often is carefully organized and formulated, nevertheless it is an opinion that simply extends the debate and argument. "The model must be seen as a generator of opinions, not answers" (Morecroft, 1984, p. 218). Decision makers should challenge the opinions underlying the model and debate the conclusions implied by it. This scrutiny provides a sharper insight into the viability of the proposal.

To facilitate long run strategic planning, the system dynamics approach to complex problems focuses on the feedback process. The underlying assumption of a feedback model is that changes over time are the result of system structure and not of external agents. If the sales curve is shaped like an $S$, it is because the dynamic behavior of the system produces such a pattern. However, there would be no reason to think that the markets for all products or services have the same system structure, although many may have similar behavior patterns over time. Without common system structures, different sales curves are possible. There very well may be a small set of generic system structures associated with homogeneous product or service markets (Meadows, 1970). It is possible that an S-curve generic system explains the PLC of the development of resort sites for tourists.

This brings the argument back to the PLC concept. If the S-curve system behavior is dominant because of system structure, then management should plan advertising promotion to attain peak market penetration and market potential through the maturity stage of the life cycle (Forrester, 1959). Advertising in the latter stages of the life cycle would bring negligible results, regardless of the strategy followed. The latter stages of the life of the development may require significant capital expenditure to transform the old service into a new concept with a life of its own, or to extend the life of the old service beyond the maturity stage of the cycle. Clearly the strategy will differ depending on the structure of the system. Therefore, strategic planning begins with research into the underlying structure of the market.

\section{Evolutionary Model of Tourism Site Development}

While there are different explanations for the cyclical behavior of heterogeneous commodities or services, several factors seem to contribute significantly to the dynamics of tourist areas (Butler, 1980). These include changes in the preferences and needs of visitors, the gradual deterioration and possible replacement of physical plant and facilities, and the change or disappearance of the natural and cultural attractions that were responsible for the initial popularity of the area. Over time, the type and volume of tourists change, the host culture changes and the reactions of community residents to tourists vary in a predictable manner with stages of tourist attraction development.

These stages of development have been noted by several authors (Butler, 1980; Cooper, 1981; Noronha, 1976; and Stansfield, 1978). The Butler formulation is based on the product cycle marketing concept. The tourism cycle is similar in all but the final stage to the product acceptance cycle that innovations experience. Sales or adoptions occur slowly at first, then expand rapidly, and stabilize asymptotically. The final stage of the product cycle is decline. While decline occurs often in the history of tourism sites, it does not appear to be the necessary condition of the mature stage of tourist areas. However, without rejuvenation, once the growth of the industry has stabilized in the region, some decline is likely (Reime and Hawkins, 1979).

The contraction stage of the life of the development is an important aspect of development strategy. What are the most likely sources of the contraction and, given the necessary lead time, how might the decline be avoided? 
There may be several causes for the decline, some internal to the organization and others that are due to the external market. Often decision makers blame the external environment for the decline when the dynamics of the organization are responsible for the stagnation. Regardless of the source, decision strategy should attempt to counteract the stagnation of the development.

Some authors believe that decline occurs following stabilization because different types of visitors are drawn to the attractions at different stages of their development. The types of visitors that appear during the consolidation and stagnation stages are considered as contributing to decline.

Tourist typologies have been developed to describe the visitors. The characteristics are bounded on one end by the visitor seeking strangeness and novelty and on the other by the visitor who wishes to travel, but within the context of familiar surroundings. The unique and strange can be experienced best during the 'exploration' stage of development of a tourist area, while a familiar environment is experienced more easily once an area has become well developed.

While tourist typologists (Abbey, 1968; Cohen, 1972; and Smith, 1977) all order their typologies along these underlying dimensions, Plog (1974) developed his typology in a way that clarifies relationships among the stages of site development, the type of visitor and the community/cultural impact on the area. Plog identified five tourist types (allocentric, near allocentric, mid-centric, near psychocentric and psychocentric). Reime and Hawkins (1979) have subsequently estimated the proportion of each type in the general population.

Plog defines the allocentric individual as a drifter or explorer. These visitors rarely return to an area for a second look. They comprise about 6 percent of the population. These visitors are not the target of the resort site developer.

Near-allocentric individuals represent approximately 15 percent of the population. They wish to see and interact with an area as it is, however, some accommodations are desired. This group would be likely to be attracted in the early development stage of the site.

The largest group, the mid-centric, comprises about 60 percent of the population. Researchers (Plog, Reime and Hawkins) speculate that this type of person seeks "security" and "peer approval" and as a consequence, seeks a well developed tourist area with a variety of commercial attributes. The near-psychocentric visitors require not only a high density commercial attraction environment but also an abundance of modern chain hotels, family restaurants, and souvenir shops. Together these visitors seek non-foreign attractions and generally those that are easy to reach.

Finally, the psychocentric individuals seek highly familiar areas. They tend to enjoy resort areas, amusement parks, family restaurants and souvenir shops. Psychocentrics require that the attraction environment be contrived to fit their interests. This type of visitor tends to be a repeat customer.

The evolutionary model of Butler can be used to characterize the development of tourism in an area and linked to the general typology described above.

Exploration Stage: This stage is characterized by small numbers of visitors, most of whom are Plog type allocentrics who arrange their own accommodations.

Involvement Stage: More visitors (near allocentrics) begin to visit the area. During the involvement stage a small tourist season may emerge, as well as an effort to organize travel accommodations. While the impacts on the area are minimal during this stage, some effects are recognized. Additional income and employment opportunities for families providing tourist services are noticed. Government agencies register the increased demand for improved public services.

Development Stage: During this stage the area emerges as a major tourist market area experiencing a tourist population that at peak periods may exceed the local population. The area becomes dependent on extensive advertising from the tourist generating sector of the regional economy. The natural and cultural features that served as the initial attractions will be replaced by artificial features. Competitors join the market, attracted by the revenue and profits of the mature resort.

This stage is marked by significant economic benefits for both local residents and external developers. During the latter stage of development major changes occur in the physical environment. During this stage of major transformation, the built-up environment becomes dense and modern. This stage is dominated by mid-centric travelers.

Consolidation Stage: During consolidation the rate of increase in visitors declines but overall numbers continue to increase. The economic impact of the tourism industry is recognized as major and highly institutionalized, with a significant effort being made to extend the season and the market area. Chain hotels, restaurants and other attractions become conspicuous. Resident reaction can become more action oriented than in any previous stage, antagonism often replaces cooperation (Doxey, 1975; Stough and Feldman, 1982). The near-psychocen- 
tric visitor defined by Plog is present during this stage.

Stagnation Stage: When stagnation is reached, the attractiveness of the site has peaked. Capacity for many factors such as attractive development locations and public services, environmental, social and economic problems are manifest. During this stage the area has a well established image but it may have become "unfashionable." Consequently, surplus or unused capacity may appear and extensive efforts may be required to maintain visitor volume. During this stage the typical area becomes almost completely dependent upon artificial attractions that frequently are foreign to its original image. To the extent that new development occurs, it is peripheral to the original core attraction area. As the period of stagnation evolves, the type of visitor changes and psychocentric travelers become more conspicuous.

Post Stagnation Stage: As an area adjusts to stagnation, it may experience one of three longer term outcomes: rejuvenation, maintenance or decline. In decline, viewed by many as the most frequent outcome (Butler), the area loses its ability to compete with other newer attractions for mid-centric visitors. The area appeals primarily to day or weekend visitors, if it is accessible. Property turnover and vacancy rates rise and properties are converted to such nontourist uses as retirement facilities or nursing homes. If this process is cumulative, the viability of the remaining tourist facilities is compromised even further.

Rejuvenation of a stagnant tourist industry usually occurs in one of two ways. First, the area may strike upon a new 'artificial' attraction, such as gambling in Atlantic City (Downey, 1982; Tantillo, 1982; and Sternlieb and Hughes, 1983). Rejuvenation also may occur through developing previously undeveloped resources. A winter ski resort may reorient its facilities as a summer golf, tennis and conference center.

Maintenance may be the most desirable goal for an area that has reached the stagnation stage. Ideally an area would maintain itself once the physical and institutional infrastructure has been built. This requires extensive physical and institutional reinvestment in repair and modemization that is not likely to happen if the area has passed through the evolutionary process described above. This is caused by the lower recurn on investment in modernization than on investments in new or emerging attractions. Areas most likely to be maintained are those that reach the consolidation and stagnation stages prematurely, stabilizing facilities at a level that is attractive to the near-allocentric and mid-centric tourists described by Plog.

The above stylized description of the evolutionary view of tourist attraction development of Butler and the visitor typologies of Plog identifies a number of focal points for strategic management policy. A system dynam- ics model designed to capture the structure and feedback associated with the evolutionary process is discussed in the following section.

\section{A System Dynamics Model of Site Development}

A system dynamics model of the theme park market was developed to serve as a tool for understanding how marketing effort, competition and industry reputation interact to shape the growth of mature companies in the industry (Fritz, 1986). The model depicts the market as it might be seen by a typical mature company, and it can be used to analyze policies that such a company might use to control market growth to its advantage. The model developed here follows closely the model of the dynamics of a fledgling growth market outlined by Morecroft (1984).

The market consists of customers who first must be informed of the tourist product and who ultimately purchase some package of services (lodging and entertainment) by selecting one of several alternatives from competing leisure activity suppliers. Attention is paid to new firms that compete at the bidding stage, once potential customers have been identified. The model examines factors that influence the startup of these new firms and their competitive behavior.

All dynamic feedback models are controlled by two types of loops (Richardson and Pugh, 1981, p. 7). Positive feedback loops reinforce the momentum of the action. If the action is expansion, the positive loop exhibits unrestrained growth. If the action is dampening, the positive loop simulates contraction. The first example of a positive loop in Figure 1 is the "Market for Established Tourism Site" loop that focuses on real growth of the mature site. As more customers are drawn to the site, new attractions are added. The new customers provide revenues for the site that are used to pay for more sales effort. The additional sales effort results in more customer interest and sales expand.

Another positive loop in Figure 1 depicts speculative growth in the "Market for New Competition" loop. The bidding power of new competitors is high initially because they seek greater market penetration. This bidding power results in customers' being won by the new suppliers and increases the utilization of the new sites. This stimulates new startups and ultimately more capacity from which to compete with the mature site.

Goal seeking also is obtained by negative feedback loops. That is, negative loops reverse the effect of the action either constraining growth or retarding contractions. While there are many feedback relations in the system, a tourist site life cycle model is dominated by five major loops, three positive and two negative. Figure 1 il- 


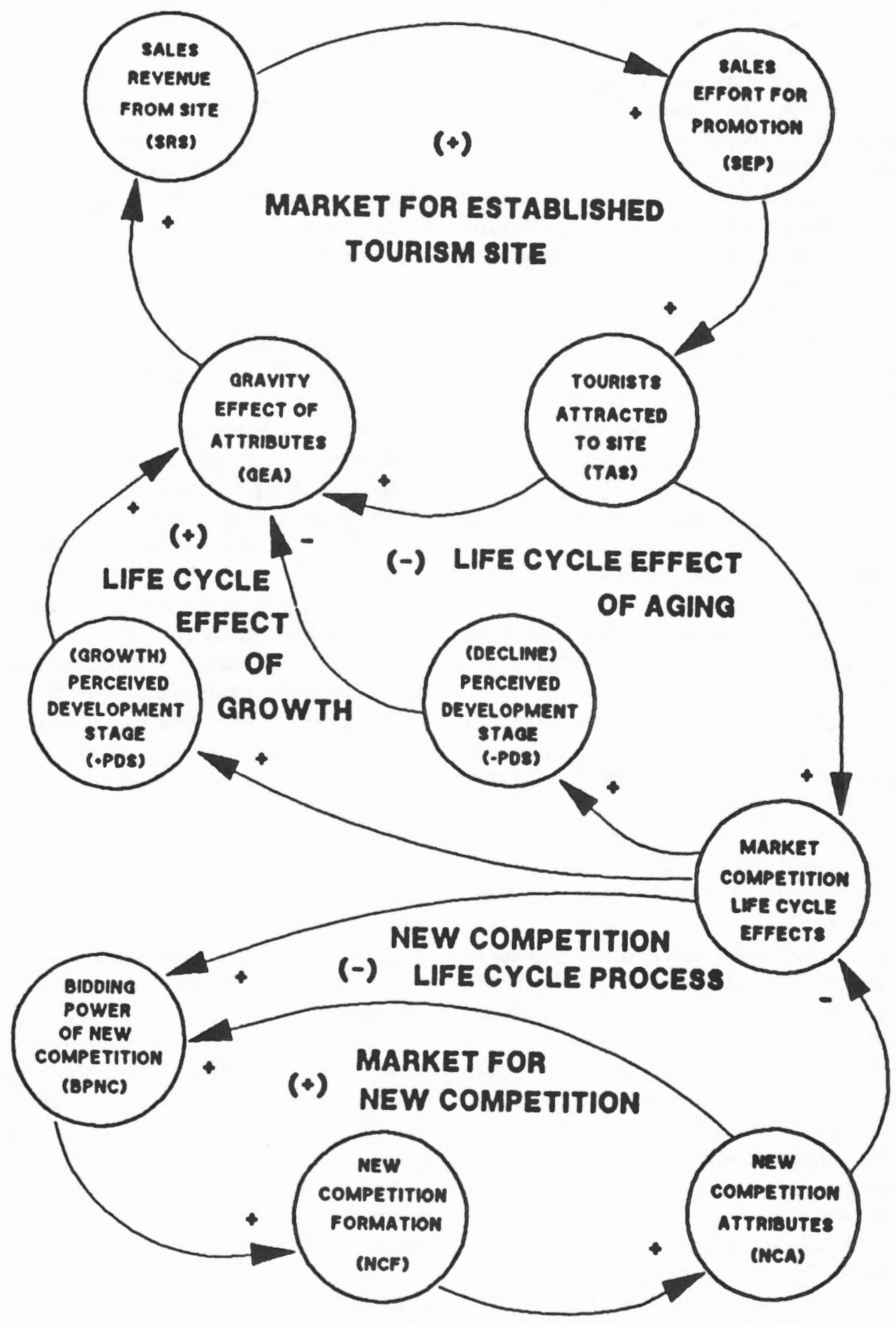

Figure 1. Flow Diagram of Dominant Loops in Life Cycle Model 
lustrates the relationships among the dominant loops.

The negative loop, "Lifecycle Effect of Aging," is based on the effect of aging on reputation. As a mature site passes through the "development" stage into "stagnation," its established reputation begins to falter. Customers shift their interest from the mature firm to the new competition. Aging acts as a constraint on expansion of the mature firm and links the positive loops "Market for Established Site" and "Market for New Competition." Notice from Figure 1 that the "Lifecycle Effect of Growth" provides positive feedback, while the "Lifecycle Effect of Aging" provides negative feedback. Further, the positive loop "Market for New Competition" is constrained by its interaction with the negative loop, "New Competition Lifecycle Process." This allows the model to consider the impact of aging on new tourist sites that are brought on line to compete with the mature site.

Figure 2 shows the complete diffusion process of the model, using system dynamics flow diagramming symbols. Six levels are represented: Tourists Attracted to the Site, Sales Effort for Promotion, the Gravity Effect of Attributes, the Established Reputation of the Site, New Competition Formation, and New Competition Attributes. The model is divided into three sections. These are shown clockwise in Figure 2: the Customer Diffusion Process with Promotion Budgeting (see close up in Figure 3), the Gravity Effect of Project Attributes and the Established Reputation of the Site (see close up in Figure 4), and New Competition Formation with the resulting New Competition Attributes (see close up in Figure 5). The model and the simulation output reported here were developed using the Stella software on a Macintosh Computer.

In Figure 3, the number of customers interested in the tourism package increases as a result of the promotional activities of the mature firm during the "development" phase. Customers learn of the product from advertising and contact with previous visitors. The inflow of tourists initially increases in some direct proportion to the effort allocated topromotion. Reduction of customers represents a natural loss of interest and the changing attributes of the site. In the absence of sustained marketing effort, the number of interested customers will fall as the impact of sales contact or advertising wears off. Diffusion of interest in this fledgling tourist attraction, therefore, depends on continual replenishment of transient customer interest rather than the spontaneous creation of interest through word of mouth that characterized earlier stages of its development. Mid-centric and near-psychocentric visitors are dominant at this stage.

Tourism attributes are assumed to be generated in proportion to the number of interested customers. The reputation of the site plays an important role both in influencing the proportion of interested customers and the rate at which they lose interest in the attraction. If the reputation is low, perhaps because recent tourism attributes have not lived up to expectations, requests will decline, and customers will lose interest in the attraction. If the reputation is high, the reverse will be true.

It is assumed that the executives in mature companies believe that a major factor in determining reputation is the average experience and name recognition of firms in the industry. Customers rarely are in a good position to judge the merits of the tourism packages offered by alternative vendors. New sites with the least experience are most likely to supply systems that do not meet the expectations of near-psychocentric visitors. To capture this idea, the model relates reputation to the share of customers won by new competition. The greater the market share of new competition, the less will be the experience and reputation of the site, and vice-versa.

Figure 4 depicts new customer interests. These are assumed to follow the aging categories associated with the tourist typologies discussed above. Customers consider the reputation of the site, access to service facilities and expected prices. The model focuses on the decision making process of customers selecting among alternative attractions and the mature attraction. Due to the uncertainty of the product, it is difficult for customers to differentiate the price/service specifications of alternative vendors.

The model represents the uncertainty and fluidity of the sales process through the concept of bidding power. New firms tend to underbid a mature site (both on price and service), in part to gain a foothold in the market and in part from inexperience. The more new firms in the industry, the higher their bidding power, and the more likely a given attraction package will be underbid. The proportion of tourists that mature firms lose to new firms rises with the bidding power of the new competition.

Figure 5 outlines the startup, formation, maturing, and failure of new firms in the industry and their competitive bidding behavior. Startup of new competition represents the decision of a firm to enter the industry and may correspond to the creation of an entirely new enterprise or to the revival of a site that previously was active in the industry but has been lying dormant for a time. Despite the costs of facilities, it is assumed that barriers to entry are quite low. Many firms in the leisure and entertainment industry have the combination of talents required for design and development of tourism sites and the financial resources for support of a promising new venture.

The decision to start a new venture usually is speculative. Entrepreneurs may be attracted to the industry by the examples of companies that already have developed sites or by rumors of the potential growth in the demand for 


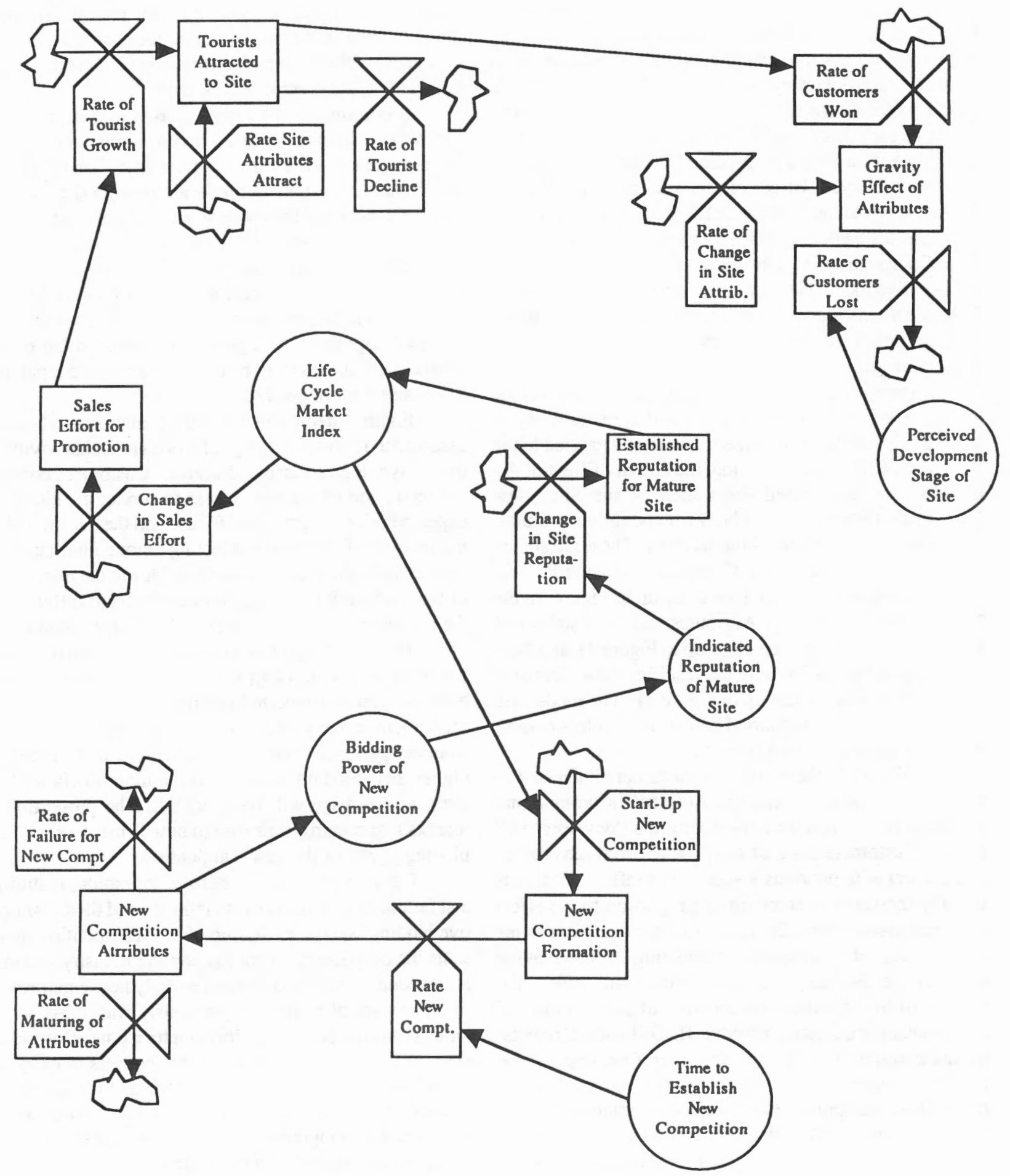

Figure 2. Major Subsystems of Site Development Model 


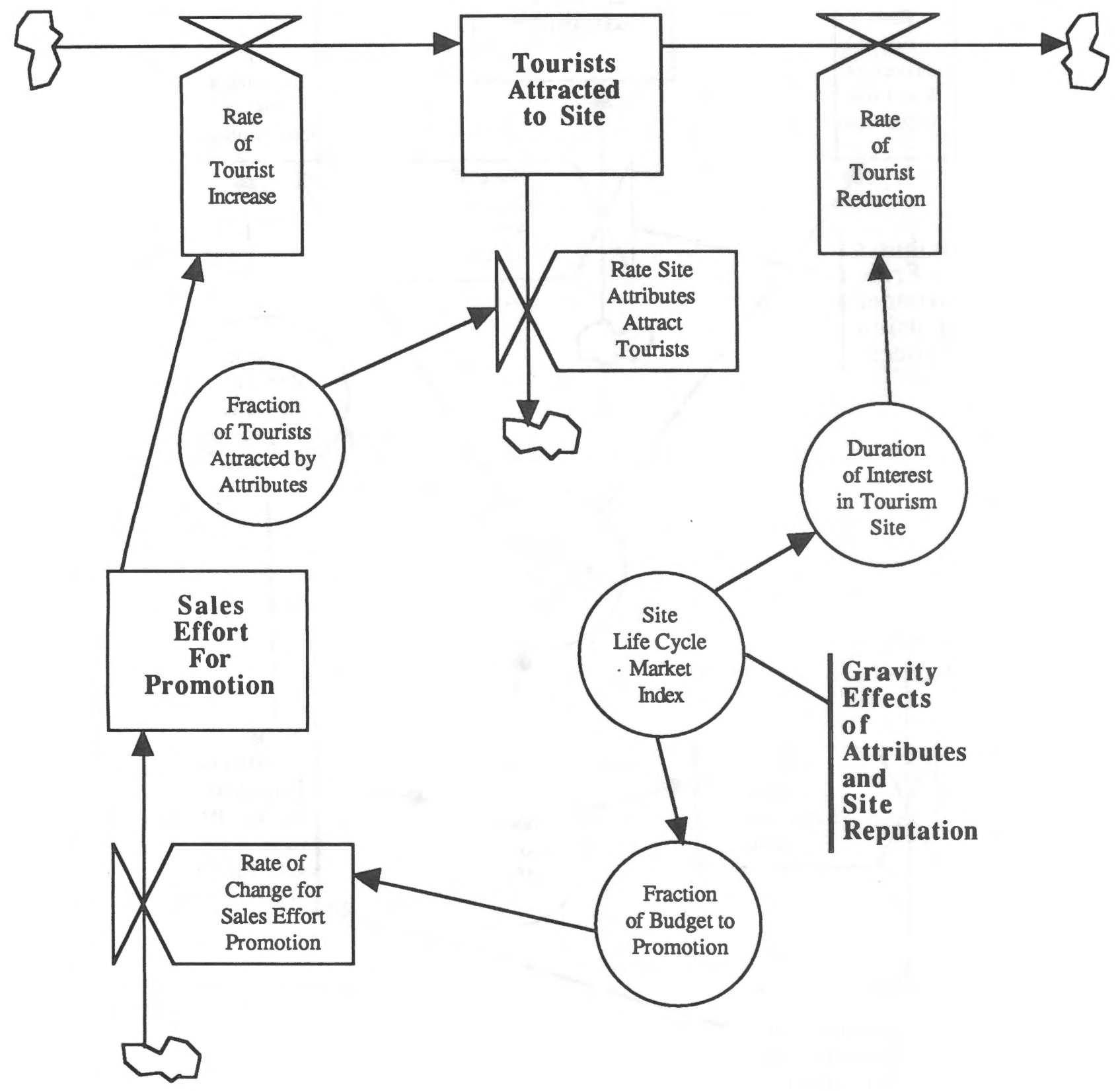

Figure 3. Customer Diffusion Process 


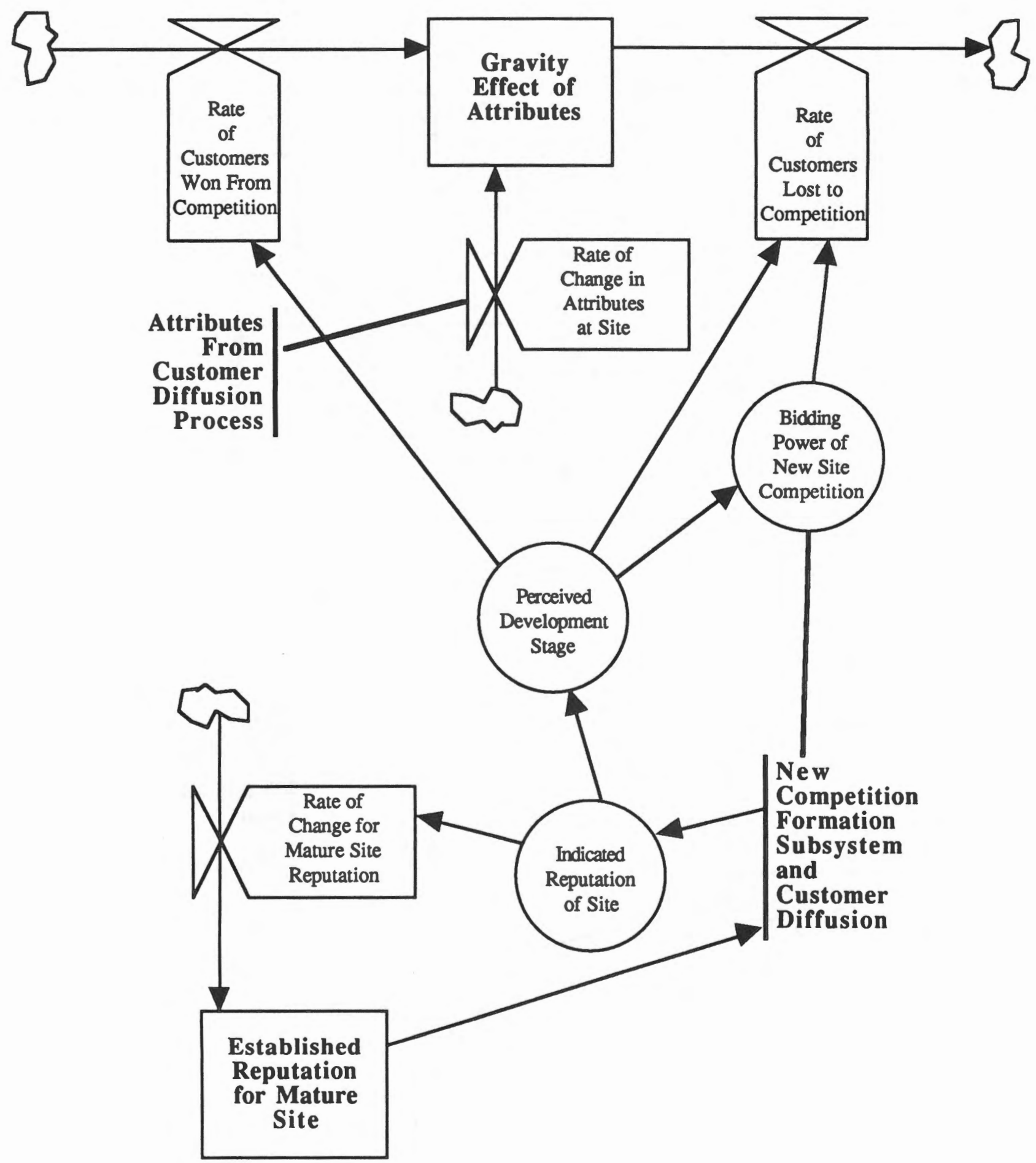

Figure 4. Gravity Effect of Attributes and Site Reputation 


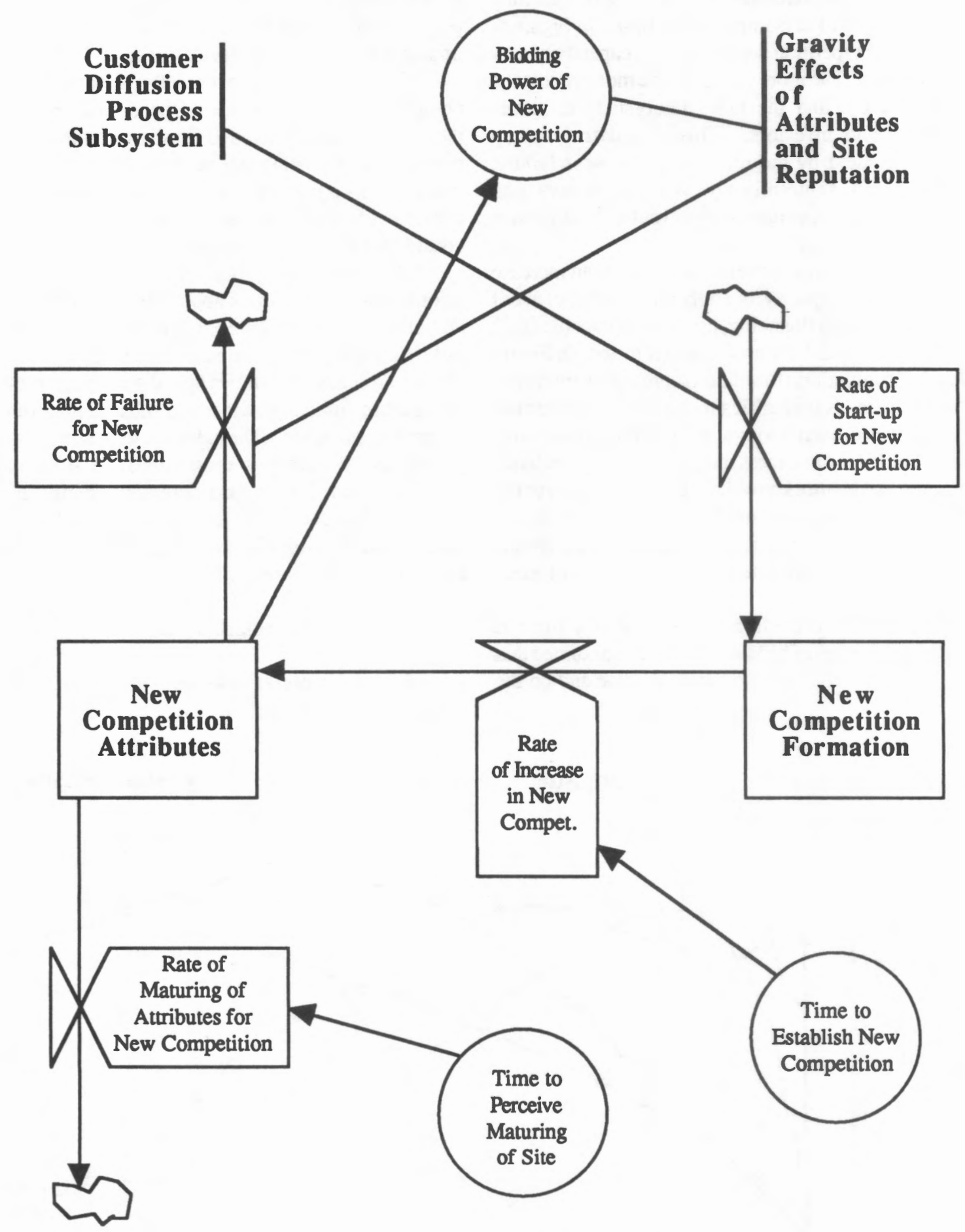

Figure 5. New Competition Formation Subsystem 
leisure activities. There is no reason to suppose that the plans of entrepreneurs are laid with full knowledge of future market size or existing industry capacity. The "invisible hand" that balances the capacity of fledgling industry with its market is imprecise at best . In Figure 5, startup of new competition depends on the capacity of new and mature firms. The more capacity, the more visible the fledgling industry, and the more likely it is to attract entrepreneurs and investors. This speculative startup process is regulated by the realities of business failure. Knowledge of failed enterprises (of which there have been many during the past several years) will deter the otherwise enthusiastic entrepreneur.

Startup of new firms eventually leads to an increase in new competition capacity, but only after a delay of about three years to arrange financing, assemble a capable staff, acquire land and install the necessary facilities. In Figure 4, the level of competition formation represents new capacity in the pipeline. It is significant that this level does not influence startup, even though many embryonic firms eventually could lead to excess industry capacity. Individual entrepreneurs cannot know the effect on capacity of the plans of all other entrepreneurs. Even if they were able to obtain this information, differences in personal risk preference would lead some to ignore or mistrust the information.

The competitive bidding behavior of new firms is captured in the concept of bidding power. It is assumed that the new firms underbid mature firms on price and on the package of services due to inexperience and a desire to penetrate the market. The model computes bidding power as the ratio of new to mature capacity. As the proportion of new competition capacity rises in the industry, bidding power rises, reflecting an increase in the frequency of underbidding the price/service package.

Successful firms eventually mature. As mature companies, they may create independent demands through their promotion efforts, and cease to be a threat from the perspective of existing mature firms (the perspective of the model). This is particularly true when the pool of potential customers is large. In such a case, the mature firms are considered to be in the "stagnation" stage.

Marketing in the tourism industry means supplying information to customers about the new attributes of the attraction and its advantages over alternative sites. The task is carried out by the sales force. The model of the marketing subsystem shows how the sales effort increases in a mature company. Since the subsystem is simple, no diagram is provided. The sales effort is allocated a fixed percentage of revenues proportional to the number of customers won, in a standard incremental budgeting procedure. The budget determines the authorized sales effort. Sales effort expenses increase actual marketing expenditures to the authorized level.

\section{Simulation Analysis}

Figure 6 reports the simulation results for the Tour-

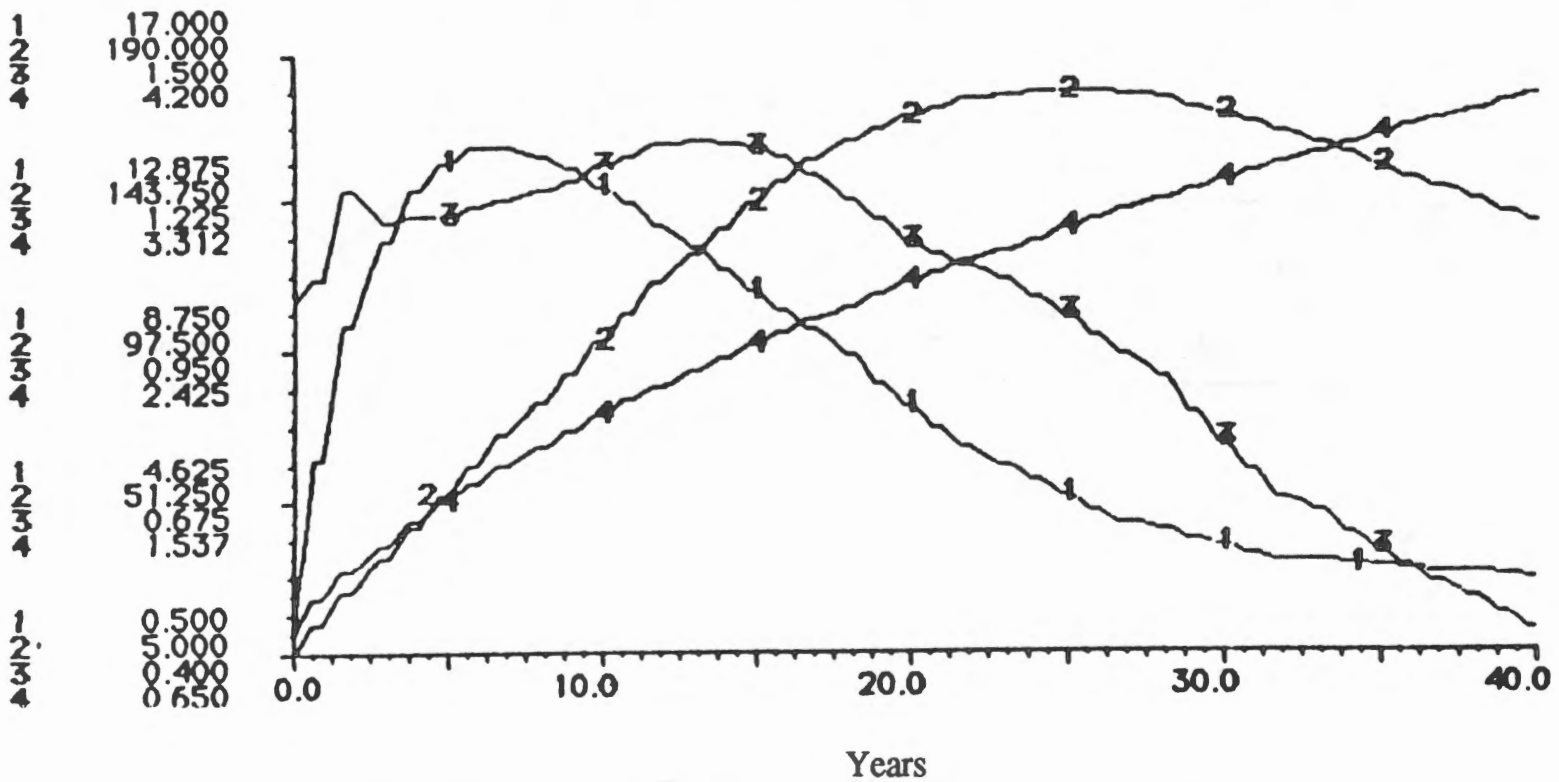

Figure 6. Simulation of Tourists Attracted to Site-Gravity Effect 


\section{TourisLAttr_Site 2 Now_Corno_Altr 3 Life_cye_MrkLUndx 4 indicaled_Repulat}

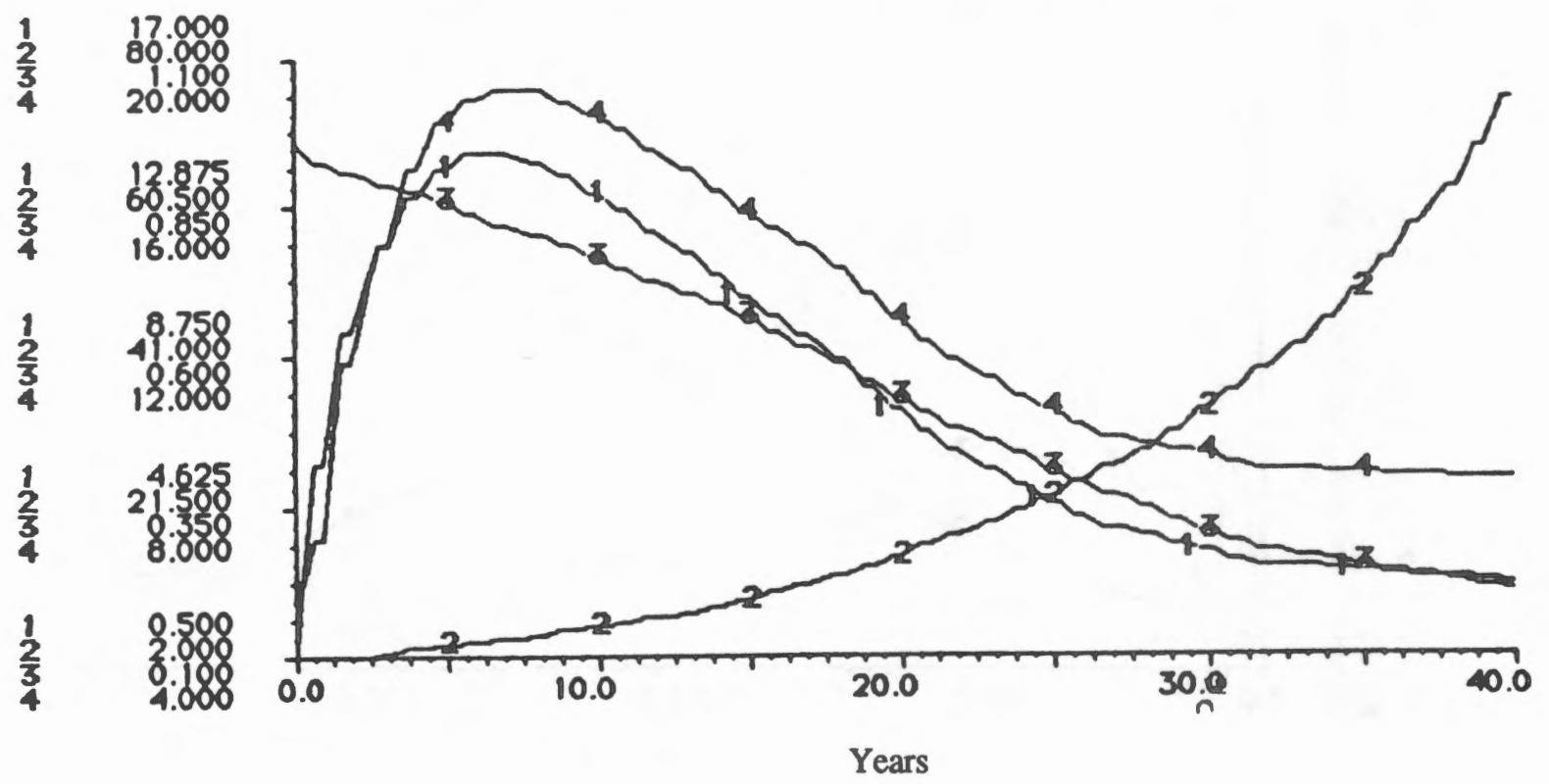

Figure 7. Simulation of New Competition and Life Cycle Index

ists Attracted to the Site, the Gravity Effect of the Attributes of the mature site, the Sales Effort for Promotion of the mature site, and the Established Reputation of the Site. After 10 years, it is clear that the site has lost its initial attractiveness. Fewer tourists are attracted each year, even with increased sales efforts (more advertising dollars) from the fifth year through the fifteenth year. The Gravity Effect of the Attributes reaches a peak at about 25 years. The continued increase in the Established Reputation of the Site indicates that the facility is viewed as constantly aging. "Rebirth" would return the site reputation to a low value to begin the aging process again.

Figure 7 contrasis the simulated Life Cycle Market Index of the mature site with the growth in New Competition Attributes. The perceptions of customers of the development stage of the mature site (Indicated Reputation) reach a peak about two years after Tourists Attracted to the Site have peaked, allowing for an information time lag. The model assumes that the mature site begins as the dominant firm with a high reputation. Thus the Life Cycle Market Index initially is high and is the inverse of the Established Reputation of the mature site (Figure 6). After 30 years, customers perceive the site as completing the life cycle and stabilizing in stagnation. The number of customers lost to the new competition continues to grow, even with expanded sales promotion by the mature site. The effect of the development cycle is too strong to be offset by marketing effort.

Figure 8 contrasts Changing Sales Effort for Promo- tion, Utilization of New Competition and Tourists Attracted to the mature site. Changing Sales Effort for Promotion has cyclical peaks about every 10 years; however, this has very little effect on capturing customers lost to new competition. Attributes of the Mature Company decline gradually through the first 15 years, then fall off rapidly in the life cycle aging process, while Utilization of New Competition accelerates after 15 years.

\section{Conclusions}

The purpose of the model employed in this study was to evaluate the life cycle of a tourist site. The model is oriented to the decision making problems of a mature tourist attraction. Aging of the facilities and the changing types of customers attracted in the various stages of the developmentare the dynamic forces included in the model. Speculative growth is assumed by new competitive firms seeking to penetrate the market. The model describes the feedbacks associated with such a market environment.

The model simulation indicates that the number of customers attracted by the mature firm will peak after about 10 years, then seek a new equilibrium at a significantly lower level. The effect of aging over the cycle does not appear to be offset by increasing promotional effort.

The model does not allow for the possibility of rejuvenation through significant changes in the character of the mature site. After 30 years, the customers perceive the site as so stagnant that maintenance after decline in 
1 Touristattr_Sito 2 Utilization Now_Com 3 Chang_Sale_En_Prom 4 Mature_Co_Altr

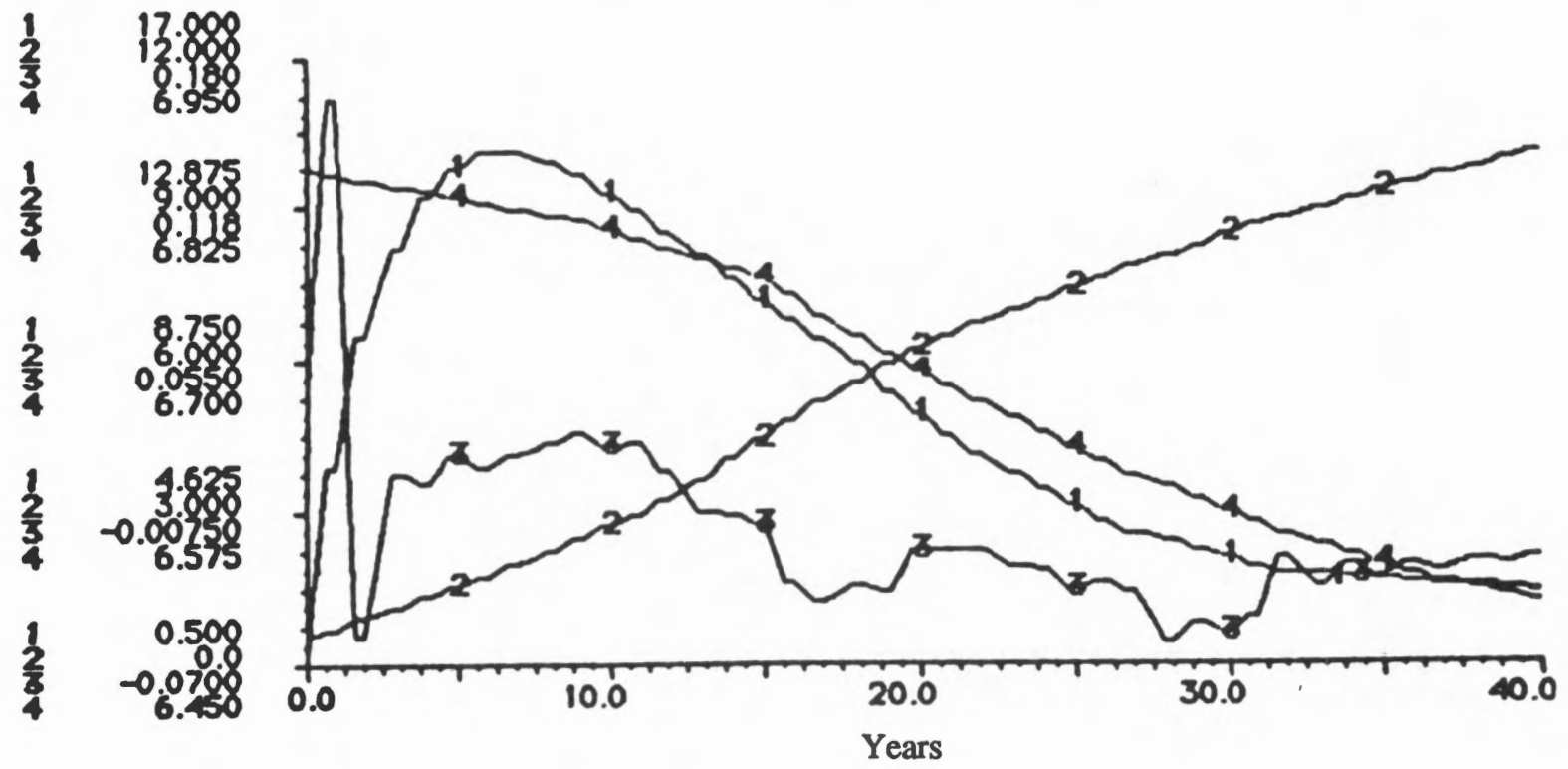

Figure 8. Simulation of Sales Effort for Promotion

reputation is possible only through extraordinary marketing effort. Rejuvenation may be possible, but it would require an effort (and expense) beyond the promotional "facelift." Restoration of the reputation of the mature site was not achieved in the simulation. However it was not the goal of this research to examine all development scenarios that are faced by tourism planners, nor to find a generic solution for site rejuvenation. Rather the objective was to demonstrate the potential value of strategic decision models that are based on the structural dynamics of the regional tourism site development process.

\section{References}

Abbey, E. Desert Solitaire. New York: McGraw-Hill, Co., 1968. Butler, R. "The Concept of a Tourist Area Cycle of Evolution: Implications for Management of Resources," Canadian Geographer, volume 1, 1980.

Cohen, E. "Towards a Sociology of International Tourism," Social Research, volume 39, 1972.

Cooper, C.P. "Spatial and Temporal Patterns of Tourist Behaviour," Regional Studies, volume 15, no. 5, 1981, pp. 359-371.

Dhalla, N. and S. Yuspeh, "Forget the Product Life Cycle Concept," Harvard Business Review, January-February 1976, pp. 102-112.

Downey, W. "Casino Gambling and the Redevelopment of Atlantic City." Paper presented at a conference at Stockton State College, Pamona, New Jersey, entitled "Allantic City Tourism and Social Change," May 3, 1982.
Doxey, G. "Visitor-resident Interaction in Tourist Destinations: Inferences from Empirical Research in Barbados, West Indies and Niagra-on-the-Lake Ontario," Unpublished paper presented to the Symposium on the Planning and Development of the Tourist Industry in the EEC Region, Dubrovnik, Yugoslavia, 1975.

Forrester, Jay W. "Advertising: A Problem in Industrial Dynamics," Harvard Business Review, volume 37, no. 2 , March/April 1959, pp. 100-110. Industrial Dynamics, Cambridge MA: The MIT Press, 1961.

Fritz, Richard G. "Dynamic Model of Regional Tourism Site Development," Les Cahiers du Tourisme, Series C, no. 99 , (February 1986), pp. 1-24.

Hart, Christopher W., Greg Casserly, and Mark J.Lawless. "The Product Life Cycle: How Useful?" The Comell H.R.A. Quarterly, volume 24, no. 4, (November 1984), pp. 54-63. Luck, David J. and O.C. Ferrell. Marketing Strategy and Plans, Englewood Cliffs, NJ: Prentice-Hall, Inc., Second Edition, 1985.

Lyneis, James M. Comporate Planning and Policy Design. A System Dynamics Approach, Cambridge, MA: MTT Press, 1981.

McTaggart, W. Donald. "Tourism and Tradition in Bali," World Development, volume 8, pp. 457-466.

Meadows, Dennis L. Dynamics of Commodity Production Cycles, Cambridge, MA: Wright-Allen Press, Inc., 1970.

Meyer-Arend, Klaus J. "The Grand Isle, Louisiana Resort Cycle," Annuals of Tourism Research, volume 12,1985, pp. 449-465. 
Morecroft, J.D.W. “The Dynamics of a Fledgling High-Technology Growth Market," unpublished manuscript, System Dynamics Corporate Research Program, MIT, February 1984.

"Strategy Support Models," Strategic Management Journal, volume 11, no. 2, Spring 1984, pp. . 215-229.

Noronha, R. Review of Sociological Literature on Tourism. New York: The World Bank, 1976.

Plog, S. "Why Destination Areas Rise and Fall in Popularity," Comell H.R.A. Ouarterly, February 1974.

Reime, M. and C. Hawkins. "Tourism Development: A Model for Growth, “ Comell H.R.A. Quarterly, May 1979.

Richardson, G.P. and A.L.Pugh. Introduction to System Dynamics with Dynamo, Cambridge, MA. The MIT Press, 1981.

Rushmore, Stephen. "The Appraisal of Lodging Facilities Update," The Comell H.R.A. Ouarterly, 25, no. 4 (November 1984), pp. 35-46.

Sheth, Jagdish N. Winning Back Your Market, New York: John Wiley and Sons, Inc., 1985.
Sirkis, Robert L. and Stephen M. Race. "Principles of Strategic Planning for the Food-Service Firm," The Comell H.R.A. Quarterly, 22, no. 1 (May 1981), pp. 35-41.

Smith, V. Hosts and Guests, Philadelphia: University of Pennsylvania, Press, 1977.

Stansfield, C. "Atlantic City and the Resort Cycle," Annuals of Tourism Research, volume 5, 1978.

Stemlieb, George and James W. Hughes. The Atlantic City Gamble, Cambridge, MA: Harvard University Press, 1983.

Stough, Roger R. and Mary Feldman. "Tourism Attraction Development Modeling: Public Sector Policy and Management," The Review of Regional Studies, volume 12 , no. 3, Winter 1982, pp. 22-39.

Tantillo, R. "Casino Gambling and Urban Redevelopment," Paper presented at a conference at Stockton State College, Pamona, New Jersey, entitled "Atlantic City Tourism and Social Change," May 3, 1982.

Wilber, Nancy and Katie Ellis (eds.) System Dynamics Newsletter. Cambridge, MA. Massachusetts Institute of Technology, 1985. 